Angelika JACOBS*

\title{
Kreuzwege der Moderne in Hellerau. Anmerkungen zu Rilke und Claudel
}

Für Theresia Birkenhauer $\dagger$

In 1912 and 1913, the Neohellenic theatre festivals of the experimental stage in Hellerau become a meeting point of the European avant-gardes. The musical stage reform of Appia and Jaques-Dalcroze was decisive for the evolution of modern drama and dance. It is, however, hardly compatible with conservative concepts of poetry, which is shown by Claudel's production of his mystery play Verkündigung (L'Annonce faite à Marie) in Hellerau and by Rilke's criticism.

En 1912 et 1913, les fêtes néo-helléniques du théâtre expérimental d'Hellerau se muent en un carrefour des avant-gardes européennes. La réforme musicale du théâtre d'Appia et de Jaques-Dalcroze, qui ouvre de nouvelles perspectives au drame et à la danse modernes, reste pourtant peu compatible avec les concepts poétiques conservateurs. En témoignent Claudel y produisant son mystère Verkündigung (L'Annonce faite à Marie) et la critique de Rilke.

\section{Bühnenkunst in der Werkstatt der Lebens- und Sozialreform}

Am Beginn der 1910er Jahre existiert in Hellerau bei Dresden eine der bekanntesten Künstlerkolonien Europas ${ }^{1}$. Es handelt sich um eines der ersten Projekte des Deutschen Werkbunds (1907-1934), der die Kooperation von Kunst, Industrie und Handwerk fördert, um die Ent-

1. Karl Lorenz: Der Traum vom <Laboratoire d'une humanité nouvelle >, in : Hellerau Symposion. Fragen zur Geschichte der Rhythmik/Des questions sur l'histoire de la rythmique, hrsg. von Reinhard Ring, Remscheid/Genf: Bundesverband Rhythmische Erziehung e.V. Remscheid, 1993, S. 23-20, hier S. 23; Gernot Giertz : Theater in Hellerau. Geschichte - Wirkung - Perspektiven, ibid., S. 55-63; hier S. 56f.

* Dr. Angelika JACOBS, Universität Hamburg, Institut für Germanistik II, Von-MellePark 6, D-20146 HAMBURG; e-mail : jacobs-angelika@web.de, www.angelika-jacobs.de 
fremdungseffekte der Massenproduktion zu mildern. Der Möbelfabrikant Karl Schmidt, Inhaber der Dresdner Werkstätten für Handwerkskunst und Mitbegründer des Werkbunds, will die Hinterhofexistenzen seiner Arbeiter durch das Wohnen im Grünen ersetzen und dabei Lebensraum und Arbeitswelt eng aneinander binden. Nach dem Vorbild der englischen Gartenstadt-Bewegung plant er seit 1908 den Neubau seiner Fabrik in Kombination mit einer Holzhaus-Siedlung nach den Ideen der Lebensreform. Dazu gehören ein Reformgasthof, Luftbäder und medizinische Einrichtungen, Spielplätze und Kindergärten sowie ein Naturtheater ${ }^{2}$. Ziel dieser konservativen Sozial- und Kulturreform ist es, die Arbeiterschaft zu bürgerlichen Kulturleistungen anzuspornen und Ansätze «geistiger Anarchie » zu überwinden ${ }^{3}$. Die Architekten Richard Riemerschmid, Hermann Muthesius und der noch unbekannte Heinrich Tessenow gestalten die Deutschen Werkstätten, die für ihre Holzveredelungsverfahren berühmt werden, nach ganzheitlichen Maßstäben, ebenso wie die Kleinhausviertel der Arbeiter ${ }^{4}$. Dem «HolzGoethe », wie man Schmidt wegen der Zusammenarbeit von Kunst und Handwerk nennt ${ }^{5}$, steht der promovierte Germanist und Ökonom Wolf Dohrn zur Seite. Dohrn ist zu dieser Zeit erster Geschäftsführer des Werkbunds. Er betrachtet Hellerau als < Laboratorium neuer Menschlichkeit >, in dem die Kunst das Wesentliche zur Lösung der sozialen Aufgaben beitragen soll. Mit seinem Bruder Harald installiert er 1910 auf einem Baugelände, das die Stadt Dresden zur Verfügung stellt, die Bildungsanstalt für rhythmische Erziehung ${ }^{6}$, zu der das 1911 von Tessenow errichtete, monumentale Festspielhaus im schmucklosen neoklassizistischen Stil gehört. Die von Émile Jaques-Dalcroze und Adolphe Appia geleitete Bildungsanstalt wird zum künstlerisch-pädagogischen Gegenstück ${ }^{7}$ der sozialreformerischen Arbeitersiedlung. Mit ihr erhält die grüne Kunsthandwerkerkolonie ihr artistisches Gesicht. Internationale Beachtung finden die künstlerischen Sommerakademien und vor allem die « Schulfeste » der Bildungsanstalt 1912 und 1913, deren Auf-

2. Mythos Hellerau. Ein Unternehmen meldet sich zurück. Katalog zur Ausstellung im Deutschen Architektur-Museum Frankfurt am Main, hrsg. von den Deutschen Werkstätten Hellerau, Frankfurt A.M. 2001, S. 54.

3. Ibid., S. 56. Ein Achteinhalb-Stunden-Tag an sorgfältig gestalteten Arbeitsplätzen, relativ hohe Löhne, unbezahlter Urlaub sowie Fortbildungen in Modellier- und Zeichenkursen und kostenlose Rhythmik-Stunden für die Kinder sind die Konditionen für die Arbeiter. Lohnkämpfe bleiben dennoch nicht aus. Die Künstler, die funktional schlichte, moderne und doch gediegene «Kunstgegenstände » für das Wohnen entwerfen, erhalten bis dato einmalige Konditionen : einen Vertrag ohne inhaltliche Auflagen, ein Produkt mit eigener Signatur und eine Gewinnbeteiligung bis zu zehn Prozent.

4. Ibid., S. 44, 58 .

5. Hans-Jürgen Sarfert: Hellerau. Die Gartenstadt und Künstlerkolonie, Dresden : Hellerau Verlag, 1999, S. 16.

6. Detlev Schneider : Orpheus tanzt rhythmisch oder Die Kathedrale der Zukunft. Ein Hellerau-Text, in : Ring (Anm. 1), S. 155-162; hier S. 158f.

7. Walter Schmitz/Annette Teufel: Helleraus theatralische Sendung, in : Dresdner Hefte, Jg. 22 (2004), Heft 79, 3/04 : Theater in Dresden, S. 58-67. 
führungen von Rhythmik-Schülern bestritten werden. Sie sollen das altgriechische Theaterfest mit der rituellen Einheit von Orchestermusik, Tanz-Chor und Dichtung wiederbeleben. Während Max Reinhardt und Hugo von Hofmannsthal am Dresdner Hoftheater den Rosenkavalier inszenieren, wird das Festspielhaus zum Treffpunkt der europäischen Avantgarden. ${ }^{8}$ Die Schulaufführung des Jahres 1913, Glucks Orpheus und Eurydike mit den Rhythmusgruppen von Dalcroze und einem revolutionären Bühnenbild von Appia, schreibt Theatergeschichte $^{9}$ :

Von den Chorszenen und Tänzen [ging] eine Wirkung aus, wie sie auch die begeistertsten Dalcroze-Anhänger schwerlich erwartet haben dürften. Nicht zu übersehen war dabei [...], daß die strenge Einfachheit der Bühne, die wunderbar weichen Farbenübergänge der Beleuchtung, die fein abgestimmten Töne der Kostüme, die ruhige Führung der schreitenden Chöre und noch mancherlei anderes in geradezu einzigartiger Harmonie sich zu einem Gesamteindrucke des Erhabenen zusammenschloß, wie er auf der Opernbühne heute nicht zu Hause ist. ${ }^{10}$

Paul Claudel, der zu dieser Zeit in Hellerau an der Inszenierung seines Mysterienspiels Verkündigung arbeitet, ist so überwältigt, dass er die eigene Premiere verschiebt: «Nie erlebte ich eine solche Einheit von Musik, Körpern und Licht. Das erste Mal seit der Zeit des Griechentums gibt es wieder eine wahre Schönheit des Theaters. » ${ }^{11}$ Tanz-Größen wie Laban und Nijinsky lassen sich in Hellerau inspirieren. Marie Rambert, neben Mary Wigman und Suzanne Perrotet ${ }^{12}$ eine der prominenten Dalcroze-Schülerinnen, wird als Nijinskys Assistentin engagiert. Sie arbeitet mit ihm in Paris die Choreographie des Sacre du printemps aus, die als Geburtsstunde des modernen Tanzes gilt ${ }^{13}$. Dass die Rhythmische Gymnastik, die sich als ganzheitliche Eurhythmik ${ }^{14}$ versteht, mehr-

8. Schneider (Anm. 6), S. 155f., 161.

9. Richard C. Beacham : Adolphe Appia. Künstler und Visionär des modernen Theaters. Deutsch von Petra Schreyer und Dieter Hornig, Berlin : Alexander, 2006, S. 139-153. 1912 kamen bereits der Anfang des zweiten Orpheus-Akts zur Aufführung sowie die Pantomime Narziß und Echo und Bach-Choreographien. Das Programm wurde zur Sensation.

10. Artur Liebscher : Die Schulfeste in Hellerau, in : Neue Zeitschrift für Musik 79 (1912), H. 28, S. 398.

11. Zit. bei Schneider (Anm. 6), S. 156.

12. Wigman und Perrotet wechseln zu Rudolf Laban, mit dem sie am Monte Verità zusammenarbeiten.

13. Da die Choreographie der Uraufführung bis auf wenige Skizzen verloren ist, kann der Einfluss von Rambert nicht genauer abgeschätzt werden. Gunhild Oberzaucher-Schüller/Elisabeth Suritz : "Die Musik durchdringt den menschlichen Körper und wandelt sich zur Freude für das Auge ». Vaslav Nijinsky und die Methode Jaques-Dalcroze, in : Bühnenkunst. Sprache - Musik - Bewegung. Kulturelle Vierteljahresschrift. 2. Jg. (1988), S. 81-85; hier S. 81.

14. Zur Eurhythmie Rudolf Steiners s. Pia Witzmann : «Dem Kosmos zu gehört der Tanzende ». Der Einflu $\beta$ des Okkulten auf den Tanz, in : Okkultismus und Avantgarde. Von Munch bis Mondrian 1900-1915 [Ausstellungskatalog]. Hrsg. von der Schirn Kunsthalle Frankfurt a.M. u. Veit Loers, Ostfildern : edition tertium, 1995, S. 600-645; hier S. 607-612. 
fach mit der Erneuerungsbewegung des Tanzes zusammengeht und weitreichende Konsequenzen für die Reform des Theaters hat, ist für den ästhetisch konservativen Jaques-Dalcroze ein unerwarteter Effekt ${ }^{15}$. Die drei experimentellen Bühnenjahre in Hellerau ermöglichen ihm die pädagogische und kreative Entfaltung seines Ansatzes ${ }^{16}$.

Wolf Dohrn realisiert mit der Einrichtung dieser einzigartigen Ausbildungsschule für das Studium von Musik und Bewegung unter der Leitung von Dalcroze seinen Plan, die Gartenstadt-Gemeinschaft zu <musikalisieren >. Der Musikpädagoge ist im Sinne eines populären Platonismus' im Reformkleid zutiefst von der sittlich ordnenden und heilenden Kraft der Musik überzeugt. Zusammen mit dem Genfer Bühnenreformer Adolphe Appia, mit dem er von 1906 bis 1923 intensiv zusammenarbeitet, will er in Hellerau ein umfassendes Reformprogramm realisieren. Nach dem externen Kursbeginn 1910 (auch für Mitglieder des Dresdner Opernensembles) ${ }^{17}$ wird die Schule im Frühjahr 1912 fertiggestellt. Durch den tragischen Tod Wolf Dohrns im Februar 1914 und den Ausbruch des Ersten Weltkriegs wechselt Dalcroze jedoch nach Genf zurück, wo er 1915 ein eigenes Institut eröffnet. Das Hellerauer Schulprojekt muss nach nur vier Unterrichtsjahren schließen. Ab 1918 entwickelt sich die Kohabitation von Kunsthandwerk, Rhythmusschule und Reformpädagogik jedoch zum Treffpunkt von Künstlern, Pädagogen und Intellektuellen aus aller Welt. 1925 zieht die Schule nach Laxenburg bei Wien um. Dort emanzipiert sich die künstlerische Tanz-Erziehung zum selbständigen Fach und entwickelt sich zu einem Zweig des Ausdruckstanzes. Nach der Machtergreifung versuchen nationalsozialistische Kräfte, das internationale Festspielhaus als « Prototypen nationalsozialistischer Baugesinnung, in dem der griechische Tempel endgültig eingedeutscht » sei, zur « artgemäße[n] Weihebühne des völkischen Dramas » umzufunktionieren ${ }^{18}$. Das Festspiel-

Steiner sieht seine Methode als Wiederbelebung der antiken Tempeltänze, dem Kern der kosmischen Mysterien, die er eingehend studiert, und fügt seinen Mysteriendramen eurhythmische Sequenzen ein.

15. Gunhild Oberzaucher-Schüller : Die Schule des Rhythmus'. Die rhythmische Gymnastik von Émile Jaques-Dalcroze und der Stellenwert des Tanzes in Hellerau, in : Tanzdrama Nr. 22/23 (1993), S. 12-17; hier S. 14. Oberzaucher-Schüller wagt die These, dass Opernszene und Theatertanz zwischen 1918 und 1933 « zu etwa zwei Drittel mittelbar oder unmittelbar von den Lehren von Jaques-Dalcroze beeinflusst war[en]. » (ibid.). S. $18 \mathrm{f}$

16. Marie-Laure Bachmann : Devant nous : Hellerau, in : Ring (Anm. 1), S. 17-22; hier

17. Beacham (Anm. 9), S. 126.

18. Schneider (Anm. 6), S. 159ff. Das kultische Bühnenkonzept Appias und der überhöhte Rhythmusgedanke von Dalcroze und Laban erleben in den Massenchoreographien der Nürnberger Reichsparteitage ihre Perversion, legitimiert durch Platon, Rousseau, Goethe, Wagner und Nietzsche. Eine Kritik ästhetischer Gruppenarrangements als « götterlose[m] mythologische[m] Kultus » mit Rückblick auf die rhythmische Gymnastik formuliert Siegfried Kracauer : Das Ornament der Masse [1927], in : ders. : Das Ornament der Masse. Essays, mit einem Nachwort von Karsten Witte, Frankfurt a.M. : Suhrkamp, 1977, S. 50-63; hier S. 62f., Zitat S. 62. 
haus wird aber kein « Opernfestspiel-Ort », sondern dient ab 1938 als Polizei-, SA- und SS-Kaserne. Nach Kriegsende übernimmt die Sowjetarmee das Objekt.

\section{Das rhythmische Gesamtkunstwerk - ein Reformfragment im $<$ antiken > Gewand}

Die Erneuerung des antiken Theaterfests ist ein Phantasma der Epoche, ebenso wie die Stilisierung des Körperbildes nach der «natürlichen > griechischen Plastik, deren Repräsentation in theatralen und tänzerischen Pathosformeln im Anschluss an die populäre Tradition des < tableau vivant > realisiert wird ${ }^{19}$. Die < lebenden Bilder > sind auch in Hellerau ein Ausgangspunkt für die Entwicklung neuer Schnittstellen zwischen musikalischer Bühnenreform, Rhythmik, Ausdruckstanz und Literatur. Die Verknüpfung von Antike-Ideal,Festspielidee und Gesamtkunstwerk ist ubiquitär ${ }^{20}$. Dalcroze und Appia wollen Schauspiel und Musik zum kollektiven Fest vereinen. Der temperamentvolle Pionier des Rhythmus' und der menschenscheue Bühnenreformer lassen die Synästhesie eines neuhellenischen Theaterfests für den historischen Augenblick der beiden großen Hellerauer Bühnenjahre, 1912 und 1913, Wirklichkeit werden. Im Zentrum steht für beide der Rhythmusbegriff. Dieser wird um 1900 als Elementarform des Zeitbewusstseins zum Ganzheitsprinzip des < Lebens > und des < Kosmos > mythisiert ${ }^{21}$ : «Es gilt mitzuschwingen, es gilt teilzunehmen mit eigenem Nerv und eigenem Sinn an dem Wellenschlag des Alls. ${ }^{22}$, ist die Maxime von Dalcroze, der sich unter anderem an Henri Bergson orientiert ${ }^{23}$.

19. Gabriele Brandstetter : Tanz-Lektüren. Körperbilder und Raumfiguren der Avantgarde, Frankfurt a.M. : Fischer, 1995, S. 90-94.

20. S. Der Rhythmus II.1 (1912) : Die Schulfeste der Bildungsanstalt Jaques-Dalcroze. Programmbuch, hrsg. von der Bildungsanstalt Jaques-Dalcroze in Dresden-Hellerau, Jena : Diederichs. Dalcroze realisiert in keiner Weise die Alterität der griechischen «musiké ». Demgegenüber thematisiert Martin Buber, der die ersten Hellerauer Experimente begleitet, die Uneinholbarkeit des antiken Ritus : Martin Buber : Das Raumproblem der Bühne, in : Das Claudel-Programm-Buch, Hellerau bei Dresden : Hellerau Verlag, 1913, S. 72-81.

21. Christine Lubkoll : Rhythmus. Zum Konnex von Lebensphilosophie und literarischer Moderne, in : dies. (Hrsg.) : Das Imaginäre des Fin de Siècle. Ein Symposion für Gerhard Neumann, Freiburg i. Br. : Rombach, 2002, S. 83-110.

22. Zit. bei Witzmann (Anm. 14), S. 604 (Zitat aus dem Jahr 1907).

23. Émile Jaques-Dalcroze : Methode der Rhythmischen Gymnastik, Paris/Neuchâtel/ Leipzig : Sandoz, Jobin \& Cie. 1906, I. Teil, Bd. 1, S. VIIIf. : «1. Jeder Rhythmus ist Bewegung./ 2. Jede Bewegung ist materiell./ 3. Jede Bewegung braucht Raum und Zeit./ 4. Raum und Zeit sind durch Materie verbunden, welche sie in ewigem Rhythmus durchzieht./ 5. Die Bewegungen der ganz kleinen Kinder sind rein physisch und unbewußt./ 6. Es ist die körperliche Erfahrung, welche das Bewußtsein bildet./ 7. Die Vervollkommnung der physischen Mittel erzeugt die Klarheit der intellektuellen Wahrnehmung./ 8. Ordnung bringen in die Bewegungen heißt den Geist zum Rhythmus erziehen. » Vgl. dagegen die einfühlungsästhetische Auffassung des Rhythmus' als Ordnungsbedürfnis der Seele bei Theodor 
Émile Jaques-Dalcroze (1865-1950) erhält erste Anregungen von dem Sänger und Musiker François Delsarte, bei dem er als Musikstudent in Paris die Klasse für Ausdrucksübungen besucht ${ }^{24}$. Richtungsweisend ist für ihn jedoch der Klavierpädagoge und Musiktheoretiker Mathis Lussy (1828-1910), der eine streng physiologisch fundierte Theorie des musikalischen Ausdrucks entwirft ${ }^{25}$. Er weckt bei dem Kompositionsschüler von Fauré, Bruckner und Délibes das Interesse an musikpädagogischen Reformversuchen. Ab 1896 entwickelt Dalcroze als Genfer Dozent für Harmonielehre eine eigene Methode der Rhythmusschulung, mit der er ab 1902 an die Öffentlichkeit tritt. Im Zentrum steht für ihn über Klang und Gehör hinaus die Körpererfahrung, die er in gymnastischen Übungen zur Musik schult. Dalcroze sieht die natürlichen Körperrhythmen durch das technische Virtuosentum des Balletts und turnerischen Drill unterdrückt. Musik und Tanz sollen wieder ganz von den vitalen Rhythmen des Körpers her gestaltet werden, denn fehlendes Rhythmusbewusstsein führt zur Trennung von Körper und Geist und zur mangelnden Entfaltung des Seelisch-Geistigen. Der Bewegungsfluss der Figuren von Dalcroze ist, verglichen mit den fixen Linien und Spannungsbögen des Balletts, einerseits relativ weich und variabel und vermittelt ein bewusstes, ungezwungenes Körpergefühl. Andererseits steht er quer zu den frei improvisierenden, visionären Tanz-Choreographien der Laban-Schule und zum ekstatischen Ausdruckstanz Isadora Duncans. Dalcroze ordnet die disziplinierten Bewegungen des Körpers stets der Musik unter und favorisiert statische Bewegungsabläufe, die dem < lebenden Bild > nahe stehen, als dynamische Tanz-Kunstwerke hingegen weniger überzeugen können. Tanz interessiert Dalcroze nur als klar analysierbares musikrhythmisches Phänomen, nicht aber als spontanes seelisches Ausdrucksbedürfnis ${ }^{26}$. Im Zentrum seiner Methode steht das unmittelbare Übersetzen

Lipps oder die phonetischen Experimente des Linguisten Eduard Sievers, der Schallanalyse und Metrik auf der Basis von Wilhelm Wundts psychophysischer Lehre der Ausdrucksbewegungen miteinander verbindet (Reinhart Meyer-Kalkus : Stimme und Sprechkünste im 20. Jahrhundert, Berlin : Akademie-Verlag, 2001, S. 73-125).

24. Delsarte entwickelt ein System für alle Ausdruckskünste, das die natürliche Interaktion zwischen Stimme, Körper und Geste fördert, und ist als Wegbereiter von Laban und Steiner zu betrachten : Michael Kugler : Die Methode Jaques-Dalcroze und das Orff-Schulwerk (Elementare Musikübung.) Bewegungsorientierte Konzeptionen der Musikpädagogik, Frankfurt a.M. u. a. : Lang, 2000, S. 78f., 90, 121ff., 132, 136; Witzmann (Anm. 14), S. 600-604; Claudia Jeschke/Gabi Vettermann : François Delsarte, in : Ausdruckstanz. Eine mitteleuropäische Bewegung der ersten Hälfte des 20. Jahrhunderts, hrsg. von Gunhild OberzaucherSchüller, Wilhelmshaven : Noetzel, 1992, S. 15-24.

25. Der Funktionszusammenhang von Gehirn, Nerven und Muskeln erhält später (im Gegensatz zu Delsarte oder Steiner) eine naturwissenschaftliche Ausprägung durch den Austausch mit dem Genfer Psychologen Clarapède und die Lektüre der Schriften von Helmholtz und Wundt (Kugler [Anm. 24], S. 35-163, hier S. 49f.).

26. Kugler (Anm. 24), S. 125ff.; ders.: Von der "Rhythmischen Gymnastik» zu den "Realisationen ». Übung und Disziplinierung des Körpers bei Émile Jaques-Dalcroze, in : Oberzaucher-Schüller (Anm. 24), S. 71-94; bes. S. 74f., 80-87; Eva Wobbe : Die Gymnastik. 
von Musik in Bewegung mit dem Ziel einer maximalen Koordination von Muskel- und Nervensystem ${ }^{27}$. Dies wird durch die Entkoppelung von Kopf-, Arm- und Beinbewegungen und die Resensibilisierung durch musikalische Schwingungen erreicht, die im Körpergewebe und im Nervensystem Resonanz finden und in Bewegungen übersetzt werden. Jedem Notenwert wird dabei eine bestimmte Bewegung und jeder Tonlage eine bestimmte Körperhaltung zugeordnet. Auf diese Weise entstehen rhythmische Automatismen, die zivilisationsbedingte Blockaden und Fehlroutinen zerstören sollen. Dalcroze spricht vom Aufbrechen der «Arhythmie », die durch eine intakte rhythmische Wahrnehmung ( «Eurhythmie») ersetzt werde, in der auslösender Nervenreiz und Muskelreaktion ausgeglichen seien ${ }^{28}$. Künstler aller Richtungen müssen ihr Gleichgewicht und ihre Bewegungen rhythmisch schulen, um dem Gefühl freien Ausdruck verleihen zu können. Dies soll letztlich auch ohne stimulierende Musik möglich sein. Die Psyche spielt dabei keine eigenständige Rolle. Die Verbindung zwischen Körper und Geist ist nach Dalcroze wiederhergestellt, wenn die Rhythmusübungen " neue motorische Gewohnheiten und neue Reflexe erzeugen, mit einem Mindestmaß von Anstrengung ein Höchstmaß von Wirkung [...] erreichen, den Geist dadurch beruhigen, den Willen kräftigen und im ganzen Organismus Ordnung und Klarheit stiften. ${ }^{29}$ Der Effekt der rhythmisch-musikalischen Übungen und Improvisationen wird von Komponisten wie Sergej Rachmaninow oder modernen Autoren wie George Bernard Shaw und Upton Sinclair gepriesen. Sinclair setzt der Künstler-Idylle in seinem Feuilleton-Roman World's End (1940) ein Denkmal. Im ersten Kapitel mit dem Titel «God's in His Heaven » schildert die Hauptfigur Lanny Budd die spektakuläre Gluck-Aufführung und beschreibt die Methode der Rhythmusschule :

In Hellerau lehrte man das Alphabet und die Grammatik der Bewegung. Man schlug den Takt mit den Armen; es gab Bewegungssätze im Drei-, im Viervierteltakt und so fort. Mit den Füßen und dem Körper gab man die Notenlänge an. Es war eine Art rhythmischer Gymnastik, so angelegt, dass der Körper trainiert wurde, schnell und genau auf geistige Eindrücke zu reagieren. Wenn man die Bewegungen der verschiedenen Tempi beherrschte, dann schritt man zu immer komplizierteren Aufgaben. Man gab mit den Füßen Dreiviertel- und mit den Armen Viervierteltakt an, man zergliederte und reproduzierte verwickelte musikalische Gebilde und stellte den Rhythmus eines dreiteiligen Kanons dar, indem man

Entwicklung der Bewegung bis zur Rhythmischen Gymnastik und deren Einfluß auf den Ausdruckstanz, ibid., S. 25-33.

27. Detailliert dargestellt bei Kugler: Übung und Disziplinierung des Körpers (Anm. 26).

28. Dalcroze versteht unter Arhythmie Störungen der Körpermotorik und des Stimmeinsatzes aufgrund eines Ungleichgewichts von nervösen und intellektuellen Funktionen (Kugler (Anm. 24), S. 139).

29. Ibid., S. 157. 
die eine Stimme sang, die zweite mit den Armen und die dritte mit den Füßen wiedergab. ${ }^{30}$

Die choreographische Umsetzung des rhythmischen Bewegungssystems erfolgt durch ein Gesten-Alphabet, mit dem Gefühle und Erlebnisse ausbuchstabiert und ganze Musikstücke in komplexe Bewegungsmuster und Gruppenarrangements übersetzt werden. Dalcroze bevorzugt die Musik Strawinskis, mit dem er die Transformationswege von Gefühl und Bewegung erkundet ${ }^{31}$. Sein Kritiker Hans Brandenburg beschreibt die Bewegungsgestaltung einer Mendelssohn-Fuge wie folgt :

Da wird die Führung der Stimmen, ihr Auseinander- und Gegeneinanderschreiten [...] zu starkem räumlichem Leben, besonders wenn sich die Oberstimmen bereits auf den Treppenstufen des Hintergrundes zum Choral aufgestellt haben und nur die Bässe noch in eiligem Lauf ein paar Figuren vollenden, bis sie sich auch zu den andern gesellen, dann der mächtige Chor, der nun gesungen wird, von den plötzlich hereintrippelnden Girlanden eines Kinderreigens umspielt ist und am Schluß das Ganze beim nochmaligen Erklingen des Fugenthemas in nachdenklichen Gruppen auseinandergeht. ${ }^{32}$

Dalcroze betrachtet die Musik als rhythmische Sequenzkette, deren Zeitmaße durch den Code der Gesten und Haltungen lückenlos in Bewegungen zu übersetzen ist. Aus der räumlichen Bewegungskoordination entsteht ein vielstimmiges Bewegungsbild, die "plastique animée ». Im Gegensatz dazu fordert Brandenburg eine spezifische Musik für die Tanz-Choreographie als eigenständige Kunstform. Beide Positionen berühren jedoch die von Isadora Duncan eröffnete Debatte um das Verhältnis von Tanz und Instrumentalmusik, die an der bildungsbürgerlichen Spaltung von < erotischer > Körperlichkeit und seelisch-geistiger < Reinheit > rüttelt. Mit ihren sehr unterschiedlichen Versuchen, absolute Musik zu tanzen, stellen Duncan, JaquesDalcroze und Brandenburg die passiven Rezeptionsmuster von Kunstmusik mit ihrer Verdrängung emotionaler Bewegungserfahrungen gründlich in Frage ${ }^{33}$.

Noch radikaler löst sich der aus Genf stammende Adolphe Appia (1862-1928), der ursprünglich Musik studiert, von den Konventionen seiner Zunft. Anders als Copeau, Reinhardt, Stanislawski, Craig ${ }^{34}$ und

30. Upton Sinclair : Welt-Ende. Roman, Bern/Stuttgart/Wien : Scherz, 1963, S. 12.

31. Sarfert (Anm. 5), S. 30.

32. Kugler (Anm. 24), S. 77.

33. Ibid., S. 77-85. Zur Einordnung von Dalcroze in die zeitgenössische Musikpädagogik und Tanzästhetik s. Joachim Gobbert : Zur Methode Jaques-Dalcroze. Die Rhythmische Gymnastik als musikpädagogisches System. Wege und Möglichkeiten der plastischen Darstellung von Musik durch den menschlichen Körper, Frankfurt a.M. u. a. : Lang 1998.

34. Zum Verhältnis von Appia und Craig s. Beacham (Anm. 9), S. 136, 149f. sowie Bettina-Martine Wolter : «Die Kunst ist die Aufführung des kosmischen Dramas ». Architekturvision und Bühnenreform 1900-1915, in : Schirn Kunsthalle/Loers (Anm. 14), S. 654-666. 
Meyerhold ist Appia, der als Homosexueller unter seiner Außenseiterposition leidet, keine unmittelbare Wirkung beschieden. Er ist jedoch als der große Visionär des modernen Theaters zu betrachten, dessen Theorieschriften und Bühnenexperimente die Grundlagen künftiger Inszenierungspraxis schaffen ${ }^{35}$. Aus der Kritik an der naturalistischen Wagnerbühne in Bayreuth entwickelt Appia seine musikalische Bühnenreform. Im Zentrum steht der singende Schauspieler, dessen Körper auch hier als Übersetzungsmedium zwischen Musik und Raum fungiert und die Bühnenatmosphäre kreiert. Appias Hauptwerk Die Musik und die Inscenierung (1899) ${ }^{36}$ sieht ihn als neuen Typus des musikalischen Turners und fordert ein choreographisches Notationssystem; er soll so trainiert sein, dass er die Musik über sein Körperempfinden in quasi marionettenhaftem Automatismus in Gesten und Bewegungen umsetzt. Damit konkretisiert Appia, weit über Wagners und Nietzsches vage Ansätze hinaus, was Dalcroze bereits als musikpädagogische Methode, jedoch ohne jeden Bezug zum Theater und ohne theoretisches Interesse praktiziert ${ }^{37}$. Er ist das eigentliche Bindeglied zwischen der Rhythmusschule und dem Festspielhaus, dessen Konzeption er technisch und architektonisch prägt. Allein seine Theatererfahrung ermöglicht die Realisierung einer Bühnenästhetik mit der Methode von Dalcroze, der zwar Musiker, aber kein Choreograph und Regisseur ist ${ }^{38}$. Appia und Dalcroze entwickeln gemeinsam ein musikalisches Bewegungs- und Raumkonzept. Bereits 1899, kurz vor Freuds Traumdeutung, konzipiert Appia in Die Musik und die Inscenierung eine Traumbildbühne, auf der alle Künste gleichberechtigt zusammenwirken. 1909 entwirft er streng geometrisch und harmonisch proportionierte Bühnenräume, die durch Licht- und Schatteneffekte an den dreidimensionalen Kulissenelementen rhythmisiert werden. Die Illusionsmalerei der Kulissen ist damit endgültig verabschiedet. Appias « espaces rhythmiques » vermitteln ein neues, abstraktes Raumgefühl ohne Illusionszwänge und Perspektivenprobleme. Kuben, Dreiecke, Podeste und Treppen dienen als mobile Bühnenbild-Elemente und formen verschiedene Spielebenen, auf denen die Schauspieler und Tänzer agieren können. Appia schlägt vor, den Rhythmik-Schülern Treppen und Stufen als Hindernisse entgegenzustellen, um ihre Bewegungsabläufe zu koordinieren und rhythmisch zu gliedern. Aus eher statischen Tableaus entwickeln sich plastische Bewegungsfolgen. Das Licht avanciert zum vollwertigen Mitspieler. Es rhythmisiert die geometrischen Flächen auf der

35. Ibid., S. 114ff. u. ö.

36. Adolphe Appia : Die Musik und die Inscenierung, mit 18 Lichtdrucktafeln, übersetzt von Princesse Elsa Cantacuzène, München : Bruckmann 1899. Wolf Dohrn würdigt den bahnbrechenden Charakter des Werkes in : Der Rhythmus. Ein Jahrbuch (hrsg. von der Bildungsanstalt Jaques-Dalcroze Dresden-Hellerau, Jena : Diederichs), Bd. I (1911), S. 20.

37. Beacham (Anm. 9), S. 125f., 185-188; Der Rhythmus II.1 (Anm. 20), S. 13.

38. Kugler (Anm. 24), S. 160-163; Kugler (Anm. 26), S. 87. 
Bühne ebenso, wie die Musik die Bewegungen der Darsteller und kann, wie bei der Orpheus-Aufführung von 1913, sogar handelnde Personen und den Ausdruck von Emotionen ersetzen ${ }^{39}$. Licht und Musik laufen im Körper als lebendigem Fokus zusammen ${ }^{40}$, der Rhythmus verbindet Bewegung, plastische Kulisse, Licht und Musik. Für Dalcroze stellt er das Heilmittel einer Reharmonisierung von Körper und Geist dar, für Appia den Königsweg zum autonomen, in sich harmonischen Gesamtkunstwerk.

Appia setzt eine entsprechende Ausgestaltung des Festspielhauses durch. Statt einer Guckkastenbühne entsteht ein durchgehend beleuchteter, undekorierter Raum, der Zuschauer und Akteure gleichermaßen umfasst und von jeder Stelle aus ganz einsehbar ist. Damit schafft Appia die erste völlig offene Spielfläche seit der Renaissance ${ }^{41}$. Durch den versenkbaren Orchestergraben - das einzige Element, das er aus Bayreuth übernimmt - gehen Zuschauer- und Spielraum nahtlos ineinander über. Frei bewegliche Sitze und Bühnenelemente lassen neue Beziehungen zwischen Darstellern und Zuschauern denkbar werden. Statt des verzerrenden Rampenlichts schafft die Beleuchtungsanlage des georgischen Bühnenmalers Alexander von Salzmann einen strahlenden Raum mit gleichmäßig über die Flächen verteilten, verborgenen Lichtquellen ${ }^{42}$. Wände und Decke des Spielbereichs sind mit einer aufwändigen Konstruktion versehen, auf der 7000 Glühbirnen installiert sind. Diese lassen sich über einen Schiebewiederstand stufenlos regeln und sind von lichtdurchlässigen Leinenvorhängen verdeckt, die das Licht streuen. Mit den verborgenen Lichtquellen sowie den kippbaren Scheinwerfern, die auf der parzellierten Decke montiert sind, können die unterschiedlichsten Raumqualitäten erzeugt werden, indem man das Licht auf den Wänden eher reflektieren oder durchscheinen lässt. Punktbeleuchtung oder diffuses Licht aus allen Richtungen, das Farben, Schatten und Konturen wirkungsvoll hervortreten lässt und eine homogene Atmosphäre schafft, sind nun möglich. Licht, Bühnenbild und Musik treten in symbolische Interaktion. Von Salzmann spricht von der Kraft des «tönenden Lichts », in dem Appias « rhythmische Räume » ihre Wirkung voll entfalten ${ }^{43}$. Er, Appia und Dalcroze sind

39. Dort erscheint Amor als Lichtstrahl auf der Bühne, während seine Stimme aus dem Hintergrund ertönt; auch die Wiederbegegnung der Hauptfiguren in den elysischen Feldern wird durch Licht symbolisiert und nicht durch expressives Spiel wiedergegeben (Beacham (Anm. 9), S. 147-150).

40. Adolphe Appia : Die Rhythmische Gymnastik und das Theater, in : Der Rhythmus I (Anm. 36), S. 57-64; hier S. 60.

41. Beacham (Anm. 9), S. 49f., 138. Die Halle fasst 560 Zuschauer und 250 Darsteller.

42. Gernot Giertz: Kultus ohne Götter. Émile Jaques-Dalcroze und Adolphe Appia. Der Versuch einer Theaterreform auf der Grundlage der Rhythmischen Gymnastik, München : Kitzinger, 1975, S. 125-129.

43. Alexander von Salzmann : Licht, Belichtung und Beleuchtung, in : Das ClaudelProgramm-Buch (Anm. 20), S. 88-91. 
die Architekten des < plastischen Rhythmus' >, in dem die verschiedenen Ausdrucksmittel so perfekt zur Stil-Einheit verschmelzen, dass das Publikum der Orpheus-Inszenierung das Bewusstsein verliert, einer Vorführung beizuwohnen ${ }^{44}$. Die Verbindung dieses musikalischen, zur Abstraktion neigenden Reformkonzepts mit dem musiklosen Sprechtheater stellt jedoch eine Herausforderung dar. Dies zeigt die von Rilke besuchte Claudel-Inszenierung drei Monate nach dem Triumph des Orpheus.

\section{Im Vorübergehn : Rilkes Hellerau}

«[D]ie Schule Dalcroze ist etwas wunderschönes, etwas das da sein muss, Reinhardt und ich sind ganz erfüllt von der Schönheit und den Möglichkeiten die darin liegen [...]. » ${ }^{45}$ - so äußert sich schon Hugo von Hofmannsthal im Dezember 1912 in einem Brief an Mechtilde Lichnowski. Hofmannsthal wird durch Helene von Nostitz mit Hellerau bekannt gemacht, bei der er nach der Dresdner Uraufführung seiner Ariadne-Oper Ende Oktober im Kleinen Haus des Hoftheaters für einige Tage zu Gast ist ${ }^{46}$. Sie ist auch die Hauptansprechpartnerin für die Eindrücke, die Rilke ein Jahr später gewinnt. Zusammen mit Lou AndreasSalomé besucht dieser am 5. Oktober 1913 die deutsche Premiere von Paul Claudels Drama Verkündigung (L'Annonce faite à Marie), zu der auch Max Reinhardt erscheint. Rilke trifft auf Annette Kolb, die Kippenbergs, Ellen Delp, Regina Ullmann, Henry van de Velde und lernt Franz Werfel kennen. Nach einer Erholungswoche im Riesengebirge wird nochmals in Dresden Station gemacht. Zusammen mit Lou und Ellen Delp lässt Rilke sich die Methode Dalcroze vorführen, bevor er nach Paris zurückreist ${ }^{47}$. Über den folgenden Austausch mit Harald

44. Beacham (Anm. 9), S. 153.

45. «Blicke, Hände, Geschriebenes, Handschrift, Gedichte - es ist ja alles ungefähr dasselbe ». Der Briefwechsel zwischen Hugo von Hofmannsthal und Mechtilde Lichnowsky, hrsg. von Hartmut Cellbrot und Ursula Renner, in : Hofmannsthal. Jahrbuch zur europäischen Moderne 5 (1997), S. 147-198; hier S. 191f.; vgl. seine Stellungnahme zu Hellerau in Der Rhythmus II.1 (Anm. 20), S. 92.

46. Frau von Nostitz berichtet ihm schon 1910 enthusiastisch von Hellerau (Briefwechsel Hugo von Hofmannsthal - Helene von Nostitz, hrsg. von Oswalt von Nostitz, Frankfurt a.M. : Fischer, 1965, S. 98, Brief v. 20.10.1910). Sie stellt Hofmannsthal Anfang 1911 auch Alexander von Salzmann vor (ibid., S. 102f., 180).

47. S. Rilkes Brief an Lou Andreas-Salomé v. 16.10.1913, in : Rainer Maria Rilke - Lou Andreas-Salomé. Briefwechsel, hrsg. von Ernst Pfeiffer, Frankfurt a.M. : Insel, 1989, S. 301f.; Rainer Maria Rilke. Briefwechsel mit Regina Ullmann und Ellen Delp, hrsg. von Walter Simon, Frankfurt/M. : Insel 1987, S. 310 : « Den 16. Oktober verbrachten wir - Lou, Rilke und ich [Ellen Delp, AJ] - wiederum in Hellerau bei Emile Jaques-Dalcroze, der uns seine neue Methode der Musikerziehung durch Körper-Rhythmik in der Darbietung seiner Schüler nahe brachte. Dann fuhr Rilke nach Paris, ich zusammen mit Lou nach Berlin [...]. » Zu dieser Zeit ist Rilke bereits ein Verehrer der Ausdruckstänzer Clotilde Derp und Alexander Sacharoff. 
Dohrn und dem Verleger Jakob Hegner ist nichts Genaues bekannt ${ }^{48}$. Auch Umfang und Verbleib der Korrespondenz mit Wolf Dohrn sind nicht $\mathrm{zu}$ rekonstruieren ${ }^{49}$. Rilke resümiert seine Eindrücke jedoch in den Briefwechseln mit Hugo von Hofmannsthal, Marie von Thurn und Taxis sowie Helene von Nostitz. Darin zeigen sich zwei Impulse : kritische Aufmerksamkeit für das theatrale Experiment und Abstand zu Claudel, dessen Werke er gleichwohl mit Interesse verfolgt. Rilke kennt L'Annonce faite à Marie schon vor der Hellerauer Aufführung, über deren Verschiebung er informiert ist ${ }^{50}$. An der Inszenierung des 5. Oktober kritisiert er die Kreuzung von Experimentierbühne, die er als « LichtRetorte » bezeichnet, und das Festspielgepräge ${ }^{51}$. Den Hellerauer Versuchen selbst steht er ebenso offen wie kritisch gegenüber ${ }^{52}$ :

Die hellerauer Leute lassen sich, als große Kinder, mit etwas ein, was sie nicht verstehen, aber, Gott weiß, vielleicht lernen sie's dabei und kommen gar nicht erst in das Trübe, das heute das Theater ist, sondern gleich auf den Grund von etwas Durchsichtigem und Reinem, das uns allen zustatten käme. Mir fiel vieles ein, worüber ich mit Ihnen und Herrn v. Nostitz einmal sprechen möchte, ich weiß nichts, als was die szenische Mauer in Orange mir beibrachte und was die zwei drei Stücke Shakespeares, die ich allein kenne, mich ahnen ließen. Wirkungen wie das Dasitzen der drei Männer und Mara vor ihnen [am Schluss der Verkündigung, A. J.], schienen mir außerordentlich wünschenswerth, nur dass eben nur eine Vermuthung gewisser Möglichkeiten dadurch gegeben war. ${ }^{53}$

Im unmittelbaren Anschluss an diese Eindrücke interessiert Rilke sich in Paris für das Théâtre du Vieux-Colombier ${ }^{54}$, das Jacques Copeau just im Oktober 1913 eröffnet. Hier steht das Verhältnis von Tradition und Innovation für ihn in einem stimmigeren Verhältnis. Copeau ist der kommende Theaterreformer Frankreichs. Noch als Theaterkritiker hat er Claudel dazu bewegt, das Hellerauer Inszenierungsexperiment $\mathrm{zu}$

48. Rilkes Brief an Lou Andreas-Salomé v. 16.10.1913, in : Rilke - Andreas-Salomé (Anm. 47), S. 313.

49. Rilke berichtet am 4.11.1913 von einem kurz zuvor eingetroffenen Brief Wolf Dohrns : Rainer Maria Rilke - Helene von Nostitz. Briefwechsel, hrsg. von Oswalt von Nostitz, Frankfurt a.M. : Insel, 1976, S. 55f.

50. Rilkes Briefe an Marie von Thurn und Taxis v. 21.3. und 14.8.1913, in : Rainer Maria Rilke - Marie von Thurn und Taxis. Briefwechsel. Zwei Bände, hrsg. von Ernst Zinn, mit e. Geleitwort v. Rudolf Kassner, Frankfurt a.M. : Insel, 1986; Bd. 1, S. 280, 308f.

51. Helene von Nostitz : Aus dem alten Europa. Menschen und Städte, hrsg. von Oswalt von Nostitz. Mit e. Vorwort v. Karl Krolow u. zahlreichen Abb., Frankfurt a.M. : Insel, 1993, S. $170 f$.

52. Rilkes Brief an Marie von Thurn und Taxis v. 21.10.1913, in : Rilke - von Thurn und Taxis (Anm. 50), S. 323f.

53. Rilkes Brief an Marie von Thurn und Taxis v. 22.10.1913, ibid., S. 51.

54. Vgl. Ingeborg Schnack :Rainer Maria Rilke. Chronik seines Lebens und seines Werkes, Frankfurt a.M.: Insel, 1975, S. 446, 448. Der Spielplan des Vieux-Colombier mischt traditionelle und moderne Stücke von der Farce über Shakespeare und Molière bis zu Claudels L'Échange : Mark Evans : Jacques Copeau, London/New York : Routledge, 2006. 
wagen ${ }^{55}$. Ab 1915 baut er intensiven Kontakt zu Craig in Florenz sowie zu Jaques-Dalcroze und Appia in Genf auf ${ }^{56}$. Rilke spricht offenbar mit Bedacht davon, dass er im Vieux-Colombier « das hellerauer Métier» weitertreiben könne und lobt die «ehrliche[n], reine[n] Art » der Inszenierungen Copeaus ${ }^{57}$. Dies ist auch als Spitze gegen das Hellerauer Regieprojekt zu lesen, dem er keinerlei konzise Kritik abzugewinnen vermag. So schreibt er an Hofmannsthal, der Claudels Werken aufgeschlossener gegenübersteht :

Die Verkündigung, Claudel, ich wüßte nichts Genaues darüber zu berichten, das ging so hin, gab zu denken, war aber so mit den hellerauer Versuchen, die auch wieder zu denken geben, vermischt, daß man nicht recht wußte, ob die Sorgen, mit denen man nachhause ging, dem Einen oder dem Anderen zuzuschreiben waren. ${ }^{58}$

Eine dezidierte Abneigung Rilkes gegen Claudel notiert Stefan Zweig schon im März 1913 nach einem Besuch in der rue Campagne Première ${ }^{59}$. Trotzdem befasst Rilke sich Ende Oktober noch mit der französischen Erstfassung der Verkündigung, La jeune fille Violaine, ohne dass sich sein Befremden verflüchtigt ${ }^{60}$. Sein Interesse mag thematisch begründet sein, da er im Januar 1912 seinen Gedichtzyklus Das Marien-Leben ausgearbeitet und im Juni 1913 publiziert hat. Die Ablehnung beruht auf Gegenseitigkeit. Claudel stellt den Autor des Cornet und des Malte rückblickend als literarischen Parvenu dar: « Ce R. M. Rilke me fit un jour une espèce de scène parce qu'il s'était aperçu que je ne faisais aucun cas de lui. Il suintait la médiocrité et la tristesse. Pas un pauvre, mais un indigent. Sa poésie est illisible. ${ }^{61}$ Rilke schreibt seinerseits nach Duino, er habe am Hellerauer Premierenabend Claudels Avancen nicht erwidert, da er mit dessen Werken nichts anzufan-

55. Claudel homme de théâtre. Correspondance avec Lugné-Poe 1910-1928, introduction de Pierre Moreau, avant-propos de Jacques Robichez, notes de René Farabet, Paris : Gallimard, 1964, p. 14.

56. Jacques Copeau : Visites à Gordon Craig, Jaques-Dalcroze et Adolphe Appia, in : Revue d'histoire du Théâtre 15 (déc. 1963), p. 357-367. Im Sommer 1916 besucht Copeau Kurse von Dalcroze und bleibt ihm eng verbunden; seine Bewunderung für Appias Werk hält ein Leben lang.

57. Rilkes Brief an Lou Andreas-Salomé v. 21.10.1913, in : Rilke - Andreas-Salomé (Anm. 47), S. 447. Rilke hat keines der Claudel-Stücke im Vieux-Colombier gesehen.

58. Hugo von Hofmannsthal - Rainer Maria Rilke. Briefwechsel 1899-1925, hrsg. v. Rudolf Hirsch u. Ingeborg Schnack. Frankfurt a.M. : Suhrkamp, 1978, S. 77f.; Zitat S. 78; vgl. Rilkes Brief an Helene von Nostitz v. 22.10.1915 (Anm. 49).

59. Rainer Maria Rilke und Stefan Zweig in Briefen und Dokumenten, hrsg. von Donald A. Prater, Frankfurt a.M. : Insel, 1987, S. 55 (Tagebuch v. 18.3.1913) : « er mag Claudel nicht, sehr aber den verstorbenen Henri Franck und auch Vildracs Découvertes. »

60. S. Rilkes Brief an Helene von Nostitz v. 22.10.1913 und deren Antwort v. 3.11.1913, in : Rilke - von Nostitz (Anm. 49), S. 50-53.

61. Tagebucheintrag v. 21.11.1939, in : Paul Claudel : Journal II (1933-1955), introduction par François Varillon. Texte établi et annoté par François Varillon et Jacques Petit, Paris : Gallimard, 1969, p. 292. 
gen wisse ${ }^{62}$. Sieht man von dem Zynismus ab, mit dem Claudel Werk und Person Rilkes zum Gipfel neuer Weinerlichkeit stempelt, so begründen beide Autoren ihr demonstratives Desinteresse mit der mangelnden emotionalen Berührung durch die Werke des anderen ${ }^{63}$. Dabei teilen sie die symbolistischen Anfänge, einen ausgeprägten lyrischen Prosastil sowie das Interesse an der Marienfigur miteinander. Rilke weiß die emotive Wirkung Claudelscher Dichtungen wohl abzuschätzen und adressatengerecht einzusetzen ${ }^{64}$. Auch wenn er am Hellerauer Premierenabend mit jener distanzierten Stille reagiert, die Helene von Nostitz in ihren Erinnerungen beschreibt, nimmt er den Impuls zur Beschäftigung mit der Theaterreform auf ${ }^{65}$, so wie er sich um 1900 mit den Dramenkonzepten Maeterlincks - einem der ersten Bewunderer Claudels - auseinandersetzt.

\section{Claudels Verkündigung}

Claudel debütiert als Bühnenautor mit L'Annonce faite à Marie, einem Drama im Geist des « renouveau catholique » ${ }^{66}$. Zunächst entsteht 1892 unter dem Titel La jeune fille Violaine eine Fassung im lyrischen Stil, der 1899 eine mystischere Version folgt ${ }^{67}$. Erst 1911 ändert Claudel den Titel in L'Annonce faite à Marie und verleiht dem schwesterlichen Rivalitätsdrama in ländlicher Idylle die fundamental-katholische Dimension eines modernen Mysterienspiels. Das Geschehen wird in ein imaginäres Mittelalter verlegt, in dem die historische Jungfrauengestalt Jeanne d'Arcs ganz im Hintergrund der Krönung Karls VII. in Reims entgegenzieht, um der Machtpolitik geopfert zu werden. Es geht um die Wiederbelebung des brachliegenden katholischen Glaubens durch den Glaubensgehorsam der Jungfrau Violaine. Ihr Handeln erscheint als Akt des Opfers, mit dem die weibliche Erbschuld getilgt wird. Diese Akzentverschiebung ermöglicht die Verbindung mit dem Erlösungswerk Marias, das für Claudel größte Bedeutung hat. Dagegen betont La jeune fille Violaine die Rolle der jüngeren Schwester Mara,

62. Rilkes Brief an Marie von Thurn und Taxis v. 21.10.1913, in : Rilke - von Thurn und Taxis (Anm. 50), S. 324f.

63. Tagebucheinträge v. 5.1.1936 und 19.10.1951, in : Claudel (Anm. 61), S. 122, 788.

64. Bei seiner ersten Begegnung mit Regina Ullmann im Oktober 1912 nimmt Rilke der tiefreligiösen jungen Dichterin die Befangenheit, indem er ihr Claudel vorträgt (Briefwechsel Ullmann [Anm. 47], S. 299f., 309f., 433). Für den Hinweis danke ich Erich Unglaub und Renate Scharffenberg.

65. Zum Interesse am modernen Theater s. Schnack (Anm. 54), S. 439 (22.8.1913), 509 (30.8.1915) passim.

66. Ein glühendes Bekenntnis zu Claudels Katholizismus formuliert Stefan Zweig: Triumph der Kathedrale (Anmerkungen zu Paul Claudels Verkündigung), in : März. Eine Wochenschrift, 7. Jg. (1913), 2. Bd., S. 416-420.

67. Die von Rilke nachgelesene Zweitfassung von La jeune fille Violaine, wird 1901 und 1911 publiziert, die erste 1926. 
die trotz ihrer mörderischen Eifersucht zum Werkzeug des Guten wird. Die Übertragung des Verlegers Jakob Hegner - einem glühenden Verehrer des Franzosen, der in Hellerau die erste Claudel-Aufführung in Deutschland ermöglicht - transponiert die Handlung von L'Annonce faite à Marie mit dem Einverständnis des Autors ins deutsche Mittelalter. Unter anderem wird dadurch das Opfer der Jungfrau von Orléans eliminiert, die politische Parallele zum religiösen Geschehen ${ }^{68}$. Der Titel lautet nun schlicht Verkündigung und deutet auf das Mysterium im Allgemeinen, während bei Claudel auf allen Ebenen der mariologische Aspekt dominiert, wie er im Brief vom 29. Mai 1913 an Jacques Rivière ausführt, dem er in Glaubensfragen als Mentor dient :

[S]i Dieu nous fait l'honneur de nous demander quelques sacrifices, il n'y a pas autre chose à faire que de les consentir avec joie. [...] Nous vivons toujours dans la vieille idée romantique que le suprême bonheur, le grand intérêt, l'unique roman de l'existence, consistent dans nos rapports avec la femme et dans les satisfactions sensuelles que nous en retirons. On n'oublie qu'une chose, c'est que l'âme, c'est que l'esprit sont des réalités, aussi fortes, aussi exigeantes que la chair (elles le sont bien davantage!) et que, si nous accordons à celle-ci tout ce qu'elle demande, c'est au détriment d'autres joies, d'autres régions admirables qui nous seront éternellement fermées. Nous vidons un verre de mauvais vin dans un bouge ou un salon et nous oublions cette mer virginale qui apparaît à d'autres sous le soleil levant. Le bien est plus difficile que le mal [...] ${ }^{69}$

Diese auf der biblischen Eva-Maria-Typologie fußende Grunddisposition ist im Konflikt der Verkündigung mustergültig umgesetzt. Die achtzehnjährige Violäne ist glücklich mit ihrem Verlobten Jakobäus. Ihr Lebensweg scheint vorgezeichnet. Überraschend trifft sie auf Peter von Ulm, der sie begehrt und versucht hatte, sie zu vergewaltigen. Er ist seitdem von Lepra befallen, was er (dem mittelalterlichen Volksglauben entsprechend) als Zeichen göttlicher Strafe empfindet. Als Dombaumeister darf er jedoch so lange arbeiten, bis der Aussatz ausbricht. Die unerwartete Wiederbegegnung von Peter und Violäne im Prolog zeigt beide als abgeklärte Persönlichkeiten, die durch ein höheres

68. Zur Eigenwilligkeit der Übertragung Hegners, die schon Thomas Mann als früher Bewunderer der Annonce, beschreibt, s. Margret Andersen : Claudel et l'Allemagne, Ottawa : Éditions de l'Université d'Ottawa, 1965, p. 94 sq. sowie die zeitgenössischen Kritiken, zit. bei Edwin Maria Landau : Paul Claudel auf deutschsprachigen Bühnen, München : Prestel, 1986, S. 55ff.

69. Correspondance Paul Claudel/Jacques Rivière 1907-1914. Texte établi par Auguste Anglès et Pierre de Gaulmyn, explications et notes de Pierre de Gaulmyn avec une introduction d'Auguste Anglès, Paris : Gallimard, 1984, S. 215f. Für Claudel selbst ist diese Position mit der Berufung zum Schriftsteller verknüpft (ibid., S. 216) : «L'amour humain n'a de beauté que quand il n'est pas accompagné par la satisfaction [...] Quant aux voluptés de l'amour satisfait, aucun écrivain ne les a jamais dépeintes, car elles n'existent pas [je ne parle pas de l'amour conjugal qui est quelque chose d'infiniment plus beau et plus profond]. J'ajoute que pour un écrivain, il n'y a pas de pire séduction que celle de l'amour, car c'est une carrière où il est absolument sûr de ne jamais réussir, à moins d'être un imbécile. » 
Schicksal verbunden sind. Peter erahnt Violänes Bestimmung : «Wer seid ihr, junges Weib, und worin ward Gott Euch so besonders offenbart,/ Daß die Hand, die sich auf Euch mit Wünschen legt,/ Und der ganze Leib verwelken,/ Als wären sie dem Geheimnis seiner Wohnung nah gekommen? » $(\mathrm{V}, 12)$. Violäne verzeiht Peter nicht nur, sie übergibt ihm auch ihren Verlobungsring aus heidnischem Gold als Spende für den neuen Dom. Zum Abschied küsst sie den Einsamen aus Mitgefühl ${ }^{70}$. Als Tiefendimension dieser selbstvergessenen Geste, mit der sie ihrem Glück ein jähes Ende setzt, erscheint in ihren Äußerungen ein diffuses Schuldbewusstsein : «Und, Peter, was gilt mehr?/ Daß Ihr meine Freude mit mir teilt, oder daß ich Euer Leid mit Euch teile. [...] Vergebt mir, daß ich so glücklich bin, daß mein Geliebter/Mich liebt, daß ich seiner gewiß bin [...] » $(\mathrm{V}, 27)$. Violäne präsentiert sich damit als Figuration Evas. Mit dem Kuss, durch den Peters Krankheit auf sie übergeht, erfüllt sie unwillkürlich Gottes Weisung : Sie tauscht ihr Liebesglück gegen tiefes Leid ein und nimmt die Ursünde ihres Geschlechts auf sich. Als sie vom Aussatz befallen wird, weigert sich Jakobäus, die göttliche Bestimmung seiner Braut anzuerkennen, die er für sich begehrt. Violäne dagegen folgt ihrem Schicksal. Sie lässt Jakobäus in dem von der eifersüchtigen Mara geschürten Irrtum, dass sie ihn mit Peter betrogen habe, und verlässt die Familie. Mara ist am Ziel, sie heiratet Jakobäus anstelle ihrer Schwester. Nach einigen Jahren gebiert sie ein Mädchen, das jedoch stirbt. Mit dem toten Kind im Arm kommt sie am Weihnachtsabend zu ihrer blinden, ausgezehrten Schwester in die Aussätzigenhöhle und fordert, dass sie es zum Leben erwecke. Sie hat die Heilige in ihr erkannt. Violäne leidet noch immer unter der Trennung von Jakobäus, akzeptiert jedoch ihr seelisches und physisches Leiden als gottgewollt :

Gott verschwendet nicht und gestattet keinem Wesen, angesteckt zu verbrennen,/ Ohne dass nicht zugleich auch ein wenig des Unreinen mitverginge,/ Des eigenen oder des fremden um einen herum, wie die Kohlenglut im angefachten Weihrauchkessel !/ Und gewiß, das Unheil unsrer Zeit ist groß./ Sie sind ohne Vater. Sie spähen aus und erkennen nicht mehr die Herrschaft und nicht mehr die Kirche./ Dies ist der Grund, warum mein Leib an der zerfahrenden Christenheit Stelle sich mühn muß./ Kraft wohnt im Leide, wenn es so freiwillig ist wie die Sünde. (V,123f.)

Violäne birgt das tote Kind unter ihrem Mantel. Unter Visionen und Engelsgesängen wird es durch die neu erwachende Kraft ihres Körpers zum Leben erweckt. Als das Mädchen sich zu regen beginnt, hat es Violänes Augenfarbe angenommen und einen Tropfen Muttermilch auf

70. Paul Claudel : Verkündigung. Ein geistliches Spiel in vier Ereignissen und einem Vorspiel. Nach der französischen Dichtung deutsch von Jakob Hegner, Hellerau bei Dresden : Hellerauer Verlag, ${ }^{3} 1913$ (künftig zit. mit der Sigle V und Seitenzahl), S. 34 : «Sie blickt ihn mit Augen voll Tränen an und reicht ihm zögernd die Hand; während er sie in der seinen hält, beugt sie sich nieder und küßt ihn. » 
den Lippen. Violäne ist mit diesem Wundergeschehen zur Figuration Evas, zur jungfräulichen Lebensspenderin Maria geworden. Maras Eifersucht ist jedoch neu entfacht. Sie lässt die hilflose Schwester in den Baugrund Peter von Ulms stürzen und begräbt sie bei lebendigem Leibe mit Sand. Peter, der vom Aussatz genesen ist, findet die halbtote Violäne und bringt sie in ihr Elternhaus. Hier erfährt Jakobäus, der sie noch immer liebt, nicht nur von der Heilung seiner Tochter und Maras Mordversuch, sondern auch von seinem Irrtum. Violäne stirbt im Kloster Marienberg oberhalb des elterlichen Gehöfts und wird im Hochzeitskleid ihrer Schwester begraben. Mara gesteht Jakobäus, Peter und dem Vater ihre quälende Eifersucht und fordert, bei Mann und Kind bleiben zu dürfen. Violänes Opfer wird zum leuchtenden Vorbild. Als Statue der Märtyrerin Justitia wird sie den Dom des Baumeisters krönen. Das Kloster Marienberg erwacht zu neuem spirituellem Leben.

Das Drama wird durch den massiven Einsatz liturgischer Elemente und sakraler Handlungen strukturiert und steht damit dem traditionellen Spiel am Altar nahe ${ }^{71}$. So indiziert die dreimalige Rezitation des Angelus jeweils eine Wendung des Geschehens, und die von Engelschören begleitete Totenerweckung ereignet sich, während Mara das Lukas-Evangelium vorliest. Die heiligen Texte fungieren wie magische Formeln und werden zum Einfallstor für das Wundergeschehen. Vermittelt wird damit die autoritative Präsenz des göttlichen Willens, der durch das Handeln und Leiden auserwählter Personen ins Werk gesetzt wird. Claudel übersetzt die liturgische Struktur der katholischen Messe, die er nach seinen Asien-Aufenthalten als dramatische Urform der europäischen Kultur empfindet, in ein poetisches Transfigurationsdrama $^{72}$. Auch der pathetisch lyrisierende Sprachduktus des Mysterienspiels dient der möglichst eindringlichen Versinnlichung dogmatischer Gehalte. Es gilt die direkte Übertragbarkeit von sakraler und poetischer Inszenierung : « [L]a foi fait vivre tout homme moderne dans un milieu essentiellement dramatique. [...] La vie est pour lui, non pas une série incohérente de gestes vagues et inachevés, mais un drame précis qui comporte un dénouement et un sens ${ }^{73}$.

Konstitutiv für das Mittelalter-Drama ist die Ausgleichsfunktion, die der weibliche Sündenbock für eine krisenhafte, glaubensferne

71. Siglinde Stiel : Die Erneuerung des Mysterienspiels durch Paul Claudel, phil. Diss. München 1968, S. 47-82.

72. Dominique Millet-Gérard: Poème biblique et poétique sacramentelle chez Paul Claudel, in : dies. : La prose transfigurée. Vingt études en Hommage à Paul Claudel pour le cinquantenaire de sa mort, Paris : PUPS, 2005, p. 301-319.

73. Paul Claudel : Le théâtre catholique. Lettre au Figaro du 14 juillet 1914, in : Euvres complètes de Paul Claudel, Bd. XV, hrsg. von Robert Mallet, Paris : Gallimard, 1959, p. 136. Claudel propagiert eine religiöse Kehrtwende in der neuzeitlichen Theatertradition (ibid., p. 161) : «L'art purement laï qui existe depuis la Renaissance a eu son temps, et l'on peut estimer qu'il a épuisé ses résultats. » 
Gesellschaft übernimmt. Diesen Zusammenhang von Gewalt und religiöser Ordnung haben der Philosoph Giorgio Agamben und der Kulturanthropologe René Girard in ihren Anthropologien des Opfers expliziert. Auch bei Claudel lebt die Figur der Violäne aus der Doppelrolle des Unruhe stiftenden, letztlich aber den Frieden ermöglichenden Sündenbocks : Im Sinne des biblischen Subtexts, der Sündenfall-Mythe, ist sie die < Ursache > von Peter von Ulms Krankheit und Jakobäus' Starrsinn. Als Eva, die den Mann zur Leidenschaft < verführt >, wird sie zum Werkzeug Gottes. Indem sie ihr Liebesglück opfert und ohne Zögern die Verlobung löst, beginnt die typologische Wandlung zur erlösenden Marienfigur. Violänes Leidensweg bewirkt ein doppeltes Erweckungswunder, das des Kindes und das des totgesagten Glaubens. Die weibliche Opferrolle wird in Claudels Originalvorlage durch die Polyvalenz des Verbrennungsmotivs zusätzlich betont : Neben Violaine, die sich in Krankheit und Sehnsucht verzehrt, verbrennt Mara innerlich vor Rivalität, während Jeanne d'Arc den realen Feuertod in der politischen Welt stirbt - Peter von Ulm hingegen wird von der < Gewalt des Weibes über seine Seele > befreit, Jakobäus geläutert (V, 160, 189f.) ${ }^{74}$. Angesichts der statischen Rollen in Verkündigung wundert es nicht, dass Rilke sich für Maras großen Geständnismonolog interessiert und die auf den Schwesternkonflikt fokussierte Zweitfassung von La jeune fille Violaine nachliest ${ }^{75}$. In Verkündigung weist die Figur der Mara die deutlichsten Ansätze psychologischer Motivierung auf. Ihr aggressiver Liebesschmerz repräsentiert die Schuldseite der Spaltungsfigur Eva/ Maria und den Schatten Violänes. In ihrer furiosen Schlussrede entfaltet sie eine komplexe Physiognomie weiblicher Eifersucht und Abhängigkeit. Vergleichbaren Themen hat Rilke sich in seinen frühen Dramen zugewandt, ebenso wie der Marienfigur in der Lyrik.

\section{Claudels Regiedebüt im Kontext}

L'Annonce faite à Marie wird zuerst von den Pariser Symbolisten begeistert aufgegriffen, die schon in den 1890er Jahren ein spirituell ausgerichtetes Theater und eine anti-illusionäre Traum-Bühne fordern. Das Stück wird Ende Dezember 1912 am Théâtre de l'Euvre von Aurélien Lugné-Poe unter intensiver dramaturgischer Begleitung Claudels

74. Vgl. Claudels Aufsatz Physique de l'Eucharistie. Das zwischen der Vernichtung des < Unreinen > und marianischer Verklärung schwankende Frauenopfer führen biographische Lesarten auf die Traumatisierung des Dichters durch die Schwester zurück, die als Modell für die dämonische Mara gilt; in Camilles Biographie stehen dagegen die konkurrentalen Vernichtungswünsche des Bruders im Vordergrund. Eine Aufarbeitung des Spannungsfeldes von Sexualität und Spiritualität bei Claudel steht aus.

75. Rilkes Brief an Helene von Nostitz v. 22.10.1913, in : Rilke - von Nostitz. Briefwechsel (Anm. 49), S. 51. 
inszeniert ${ }^{76}$. Die wider Erwarten erfolgreiche Inszenierung des Mysteriendramas rehabilitiert die ins Abseits geratene Symbolistenbühne. Das Spiel findet in unüblich schlichtem Dekor statt, dessen dunkle Atmosphäre von farbigen Scheinwerfern animiert wird. Durch schnelle Szenenwechsel verdichtet sich der Eindruck eines akustischen Ganzen. Die Kritik lobt Claudels Dialoge und die gregorianischen Begleitgesänge als ausdrucksstark, rhythmisch suggestiv und bühnentauglich; andere Stimmen tadeln die psalmodierende Überdehnung der Wortwechsel, die symbolische Überfrachtung des Bühnenbildes und die starren Gesten der Schauspieler ${ }^{77}$. Eine vergleichbare Betonung des Mysteriencharakters hat es in späteren Inszenierungen nicht mehr gegeben, wohl aber in der Hellerauer Aufführung, für die Claudel zusammen mit Alexander von Salzmann Regie führt ${ }^{78}$. Das Hellerauer Projekt wird als eine Art Vorpremiere für die Inszenierung gehandelt, die Max Reinhardt für Dezember 1913 in Berlin plant, aber nicht realisiert $^{79}$. Claudel selbst misst dem Hellerauer Experiment größte Bedeutung zu und möchte seine Erfahrungen in die Zusammenarbeit mit Lugné-Poe übertragen. Reinhardt wird um Darsteller gebeten ${ }^{80}$. Die Stilbühne stellt für die Schauspieler des Sprechtheaters jedoch ein Problem dar ${ }^{81}$. Da Dalcroze die Mitwirkung seiner rhythmischen Gruppen verweigert, lässt Claudel sich enthusiastisch auf ein Minimum an Kulissen und Kostüm ein und zählt auf die Wunder der Salzmannschen Lichtregie. Gespielt wird auf drei Ebenen, die den Aufstieg vom Irdischen und Körperlichen ins Geistige und Transzendente symbolisieren. Bei dem Versuch, die mittelalterliche Simultanbühne in die Moderne zu übertragen, hilft Claudel das Treppensystem der Orpheus-Bühne. Es ermöglicht die Verzahnung der Szenenfolge in einem Handlungsstrom mit fließenden Wechseln zwischen der irdischen und der göttlich regier-

76. Die Kooperation mit Lugné-Poe ist dokumentiert in : Claudel homme de théâtre (Anm. 55), p. 88-99. Die Uraufführung findet am 20.12.1912 in der Salle Malakoff statt (Paul Claudel : Mes idées sur le théâtre. Préface et présentation de Jaques Petit et JeanPierre Kempf, Paris : Gallimard, 1966, p. 221). Wichtiger als die widersprüchlichen Datumsangaben zur Premiere ist die Platzierung des Stückes in der Weihnachtszeit. Einerseits wird damit der intendierte Katholisierungseffekt erzielt, andererseits entstehen in katholischen Kreisen Zweifel an Claudels Rechtgläubigkeit (ibid., p. 125f.).

77. Zur Pariser Premierenkritik s. Stiel (Anm. 71), S. 137ff.

78. Ibid.; Landau (Anm. 68), S. 50.

79. Ibid., S. 140. Reinhardt, der sich neben Hegner um die deutsche Erstaufführung der Verkündigung beworben hatte, interessiert sich auch für Goldhaupt (s. Claudels Brief v. 6.10.1913 an Lugné-Poe, in : Claudel homme de théâtre [Anm. 55], p. 129f.) und später für Das Buch von Christoph Columbus (Welttheater Reinhardt. Bauten, Spielstätten, Inszenierungen, hrsg. von Max Huesmann, München : Prestel, 1983, Nr. 659, 2581). Er hat keines der Projekte realisiert.

80. Claudel homme de théâtre (Anm. 55),p. 120,247. Vorgesehen sind Alexander Moissi, der aber nicht auftritt, und Tilla Durieux für die Rolle der Mara, die von einer brillianten Mary Dietrich übernommen wird. Dietrich spielt die schwach besetzte Hauptfigur in den Hintergrund und muss in der letzten Vorstellung die Hauptrolle übernehmen.

81. Wolf Dohrn : Claudels Verkündigung in Hellerau, in :Das Claudel-Programm-Buch (Anm. 20), S. 82-87; hier S. 82f. 
ten Sphäre bei permanenter Präsenz der Darsteller. In dieser Fusion von Stufen- und Mysterienbühne ${ }^{82}$ wird die figurale Spaltung des Frauenbildes in der Zuordnung der weiblichen Physis zur unteren und der asexuellen Heiligkeit Violänes zur oberen Ebene visualisiert. Eine besondere Akzentuierung erfährt das religiöse Pathos der Wandlungsszenen. Während der Jungfrauengeburt ist Violäne von einem farbig anlaufenden gothischen Lichtbogen umgeben. Nach ihrem Tod fährt sie wie Maria in den Himmel auf. Ihre Silhouette erscheint vor einem groBen Lichtkreuz, das durch das Firmament aus Stoffbahnen leuchtet ${ }^{83}$. Die Lichtregie unterstreicht damit nicht nur die transzendenten Brennpunkte des Geschehens, sie stellt allererst die Verbindung zwischen Wortdrama und Bühnenraum her, die in Hellerau sonst durch Musik und Tanz erfolgt. Von Salzmann setzt das Licht im Sinne einer Choreographie ein, deren Effekte nicht nur Rilke als überzogen empfindet ${ }^{84}$. Claudel dagegen sieht den gewünschten Effekt einer doppelten Lesbarkeit der alltäglichen Realität erreicht : Die Allgegenwart des Mysteriums lasse den Herd zur ewigen Flamme, den Tisch zum Altar und die Tür zum Himmelstor werden ${ }^{85}$. Sein liturgischer Stil und das religiöse Konzept des Stückes werden in ein monumentales Symbolgeschehen transferiert. Ende September kündigt er Lugné-Poe ein hochkarätiges Theaterereignis an, in dem er seine Inszenierungsideen vollständig umgesetzt habe : «Il n'y a plus d'autre théâtre possible. » ${ }^{86}$ Von nun an wird er architektonische Stufenbühnen entwerfen und den Chor singender und tanzender Schauspieler in sein Repertoire aufnehmen, auch wenn er sich später von der Hellerauer wie von der Pariser Premiere distanziert ${ }^{87}$.

Beim weithin angekündigten Festspiel des 5. Oktober handelt es sich um ein Unterfangen, dessen Risiko den Hellerauer Veranstaltern bewusst ist. Die einigermaßen wohlwollende Aufnahme der Premiere gilt mehr dem aufsteigenden Theaterstern des Diplomaten-Dichters als seinem Stück. Völlig ungeschminkt äußert sich Appia im Brief an seinen Cousin Henri Odier vom 21.10.1913. Er spricht von der «Narr-

82. S. Alexander von Salzmanns Skizze zum letzten Akt in Claudel homme de théâtre (Anm. 55), p. 128.

83. S. die detaillierte Beschreibung der Hellerauer Inszenierung in der Pariser Theaterzeitschrift Comøedia vom 4.10.1913 (Paul Claudel : Théâtre II. Édition revue et augmentée, textes et notes établis de Jacques Madaule et Jacques Petit, Paris : Gallimard, 1956, p. 1384-1386).

84. Der Dresdner Expressionist Wolf erklärt Claudels «bengalische»Verkündigung zur «Stimmungsmache » eines «Mysterienspuks », der die dichterische Sprache um ihr Wirkungspotential bringe - Friedrich Wolf : Vom Untergang der Sprache, in : Auf wieviel Pferden ich geritten... Der junge Friedrich Wolf, hrsg. von Emmi Wolf und Brigitte Struzyk, Berlin/Weimar : Aufbau-Verlag, 1988, S. 75-92; hier S. 78f., 84). Für den Hinweis danke ich Cynthia Schwab.

85. Claudel (Anm. 83), p. 1384ff.

86. Claudel homme de théâtre (Anm. 55), S. 127 (Brief an Lugné-Poe v. 29.9.1913).

87. Landau (Anm.68), S. 38, 50. 
heit » des Franzosen, «sich eines Saales und eines Materials bedienen zu wollen, die genau der Darstellung eines großen Entwurfes entsprechen, und die nur von diesem Entwurf und durch ihn leben, um an seine Stelle das alte deklamatorische Spiel und Cie zu setzen $!{ }^{88}$ Wolf Dohrn verweist im Programmbuch, einem Manifest der Hellerauer Bühnenästhetik, klar auf die Differenzen zur Mysterienbühne ${ }^{89}$. Das Missverhältnis von sakralem Drama und moderner Inszenierung wird Zielpunkt der Kritik. Wenn das Stück weltanschauliche Zustimmung findet, ist dies mit der Ablehnung des Stilbühnenexperiments verbunden. So würdigt Fritz Engel für die Zeitschrift Das Theater Claudels urchristlichen Gestus im Stil Tolstois, bemängelt aber die fehlende Atmosphäre der Andacht im Bühnenbild. Zusammen mit der <weitschweifigen > Dichtung Claudels rufe dies beim Zuschauer Ermüdungserscheinungen hervor, die aus Gottesdiensten bekannt seien ${ }^{90}$. Ähnlich votiert Ulrich Rauscher in der Schaubühne. Angesichts der Spannung zwischen dem Puritanismus Appias und der sakralen Fülle des katholischen Wandlungsdramas wird mit dem Autor gegen den Regisseur Claudel argumentiert, dass das Stück « mit aller geheimnisvollen Pracht der triumphierenden Kirche » und nicht mit Lichteffekten auszustatten sei, die die Wirkung des < reinen Wortes > konterkarierten; die Lichtregie der Jungfrauengeburt führt im Vergleich mit der Gluck-Aufführung von 1912 zu dem vernichtenden Urteil, dass man diesmal kein Festspiel, sondern «Schmieren-Volksszenen » geboten habe ${ }^{91}$. Wird umgekehrt die Musikalisierung der Darstellung gewürdigt, geschieht dies tendenziell ohne Ansehen der Inhalte. Für Claudels Freund Darius Milhaud entwickelt sich das Drama durch den Verzicht auf illusionistisches Dekor wie eine weite Melodie und offenbart seinen < inneren Rhythmus $>{ }^{92}$.

Weder die Premiere noch die folgenden Aufführungen können als Erfolg bezeichnet werden. Rilke gehört zu dem Teil des Publikums, der mit Überraschung und Ablehnung reagiert. Dalcroze und Appia sprechen offen von einem Fiasko. Auch wenn das Programmbuch den gemeinsamen Willen zum großangelegten Bühnenexperiment dokumentiert, betont Wolf Dohrn darin klar und deutlich die Inkompatibili-

88. Ibid., S. 57.

89. Wolf Dohrn : Claudels Verkündigung in Hellerau, in : Das Claudel-Programm-Buch (Anm. 20), S. 82-87; hier S. 84f.

90. Fritz Engel : Paul Claudels Verkündigung, in : Das Theater 5 (1913/14), S. 72ff. Auch Wolf (Anm. 84, S. 85) polemisiert gegen « Gruppenstellen » und «Bibelstunde ». Dem eindringlichen Sprachstil Claudels, der den versifizierten Text nach musikalischen "Aufregungseinheiten » phrasiert, verschließen sich jedoch nur wenige Kritiker (Paul Claudel: Uber die Darstellung meiner Dramen, in : Das Claudel-Programm-Buch [Anm. 20], S. 69ff., hier S. 70).

91. Ulrich Rauscher : Hellerau, in : Die Schaubühne 9 (1913), Nr. 42; vollst. Nachdruck der Jahrgänge 1905-1918, Königstein/Ts. : Athenäum, 1980, S. 1003-1006; Zitat S. 1003.

92. Giertz (Anm. 42), S. 177. 
tät des hierarchischen und illusionistischen Raums der Mysterienbühne mit der Hellerauer Idee lebendiger raumsymbolischer Ganzheit. Die Brücke zur Kunstautonomie der experimentellen Avantgarde ist mit Claudels Verkündigung nicht zu schlagen.

\section{Pathos der Gebärde, Poetik des Raumes : Maria im Experiment}

Im Gegensatz zum musikalischen Reformanliegen der RhythmusSchule von Dalcroze fühlt sich Rilke von der Inszenierung der Verkündigung im Festspielrahmen nicht angesprochen. Sein Interesse an den Experimenten der Stilbühne Appias - theatergeschichtlich gesehen die avancierteste Lösung für das Inszenierungsproblem des lyrischen Dramas ${ }^{93}$ - bleibt aufgrund der unglücklichen Mischung mit dem Claudelschen Mysterium eher verhalten. Rilke selbst gestaltet vergleichbare Sujets im intimeren Rahmen, wie die Laienaufführung von Maeterlincks Singspiel Schwester Beatrix (Sœur Beátrice, 1901) zur Neueröffnung der Bremer Kunsthalle 1902 zeigt. Schon die Wahl dieses Stücks verdeutlicht den Kontrast zu Claudel. Die populäre Geschichte von der abtrünnigen Nonne Béatrice ${ }^{94}$ resümiert Ludwig Feuerbach in seinem Essay Ueber den Mariencultus von 1842 :

[F]ür eine Klosterküsterin, die aus Weltlust ihrem Kloster entsprungen, functionirte die gutmüthige Maria selbst so lange, bis die Verirrte das Leben im < sündentrunkenen Weltgebiet > herzlich satt hatte und nun, weil geistig und leiblich aufs Erbärmlichste heruntergekommen, wieder fähig und bereit war, in den Stand einer Betschwester einzutreten. ${ }^{95}$

Bei Maeterlinck setzt Maria das strafende patriarchale Prinzip durch eine Szene ekstatischer Freude außer Kraft ${ }^{96}$. Wie eine mütterliche Naturgottheit füllt sie den Raum mit einem überirdischen Blütenmeer und Gesang. Das Blumenwunder ergreift und verstört die Nonnen und Priester zutiefst. Sie halten Maria für ihre Béatrice, die ihr aufs Haar gleicht. Diese kehrt nach 25 Jahren voll Angst vor den Strafen der Hölle

93. Zum Verhältnis von Dichtung, Sprachreflexion und Theater-Moderne s. Theresia Birkenhauer : Schauplatz der Sprache - das Theater als Ort der Literatur. Maeterlinck, Čechov, Genet, Beckett, Müller, Berlin : Vorwerk 8, 2005.

94. Maurice Maeterlinck : Schwester Beatrix. Nach einer alten Klosterlegende, in : ders. : Zwei Singspiele. Blaubart und Ariane. Schwester Beatrix. Deutsch von Friedrich OppelnBronikowski, 2. verb. Aufl. Jena/Leipzig : Diederichs, 1904, S. 41-84. Maeterlincks, Claudels und Rilkes Beschäftigung mit der Marienfigur wurzelt in der Konjunktur der Marienfrömmigkeit im 19. Jahrhundert, die 1854 mit dem Dogma der unbefleckten Empfängnis sanktioniert wird.

95. Ludwig Feuerbach: Ueber den Mariencultus. Die Glorie der heiligen Jungfrau Maria. Legenden und Gedichte durch Eusebius Emmeran, 1841, in : ders. : Erläuterungen und Ergänzungen zum Wesen des Christenthums, durchges. und hrsg. von Wilhelm Bolin, Stuttgart-Bad Cannstatt : frommann-holzboog, 1960, S. 195-211; hier S. 201.

96. Maeterlinck (Anm. 94), S. 54f. 
ins Kloster zurück und stirbt zu Füßen der Marienstatue, ohne das Wechselspiel der Muttergottes realisiert zu haben. Erkannt wird Maria in der Rolle der Küsterin nur von den Kindern und Armen, deren Sensorium offen für die Erfahrung des Heiligen ist. Maeterlinck lenkt die Aufmerksamkeit auf den fehlenden Zugang zur marianischen Erfahrung von Liebe und Vergebung, Freude und Fülle der Natur. Mit der Darstellung eines verkümmerten < sensus mysticus > und der Klosterflucht wird die unterdrückte sinnliche Erfahrungsseite des Heiligen eingefordert. Claudel dagegen macht deren Domestizierung zur Voraussetzung für die Rekatholisierung der Moderne. Maeterlinck und sein Vorbild Gottfried Keller ${ }^{97}$ integrieren die Dissoziation von Sinnlichem und Heiligem aus der Eva-Maria-Typologie durch die Identifikationsfigur der Ebenbildlichkeit. Claudels Verkündigung schreibt die patriarchale Spaltungsfigur in der Koppelung von Frauenopfer und doppeltem Erweckungswunder sowie in der Gegenbildlichkeit der beiden Schwestern fort. Für Rilke stellt Maeterlincks Mariendrama einen Prototyp seines mythopoetischen Verfahrens dar, das er in den Kontrafakturen seines Marien-Lebens erneuert. Hier wird das Gedicht zum szenischen Raum der vollsinnlichen < Wandlung >, mit welcher sich die Verschränkung immanenter und transzendenter Erfahrungen im $<$ Weltinnenraum > ankündigt.

Dies illustriert die Ikonologie zentraler Pathosformeln aus dem Marien-Leben im Vergleich mit analogen Passagen der Verkündigung. Sowohl Das Marien-Leben als auch die Darstellung des Erweckungswunders und der Himmelfahrt Violänes in der Hellerauer Aufführung zitieren Vorbilder der Malerei ${ }^{98}$. Claudels Schlüsselszenen bestehen aus pathetischen Tableaus : Die Jungfrauengeburt zeigt Violäne in einer Haltung, in der sich Merkmale einer Pietà und Schutzmantelmadonna mit Anzeichen visionärer Ekstase mischen; den Engelschor symbolisiert ein farbiger Lichtbogen, die Erweckung des Kindes vollzieht sich als Transsubstantiation im Körper Violänes. Das Ergriffenwerden durch das Göttliche geschieht im Entrückungszustand, während der Lektüre heiliger Texte, die Jesus als fleischgewordenes Wort und Maria als Gnadenfigur preisen, mithin als rituelle Wiederholung

97. Gottfried Kellers Erzählung Die Jungfrau und die Nonne (1872) stellt die Hauptquelle für Maeterlincks Singspiel dar (Maurice Maeterlinck : Euvres III. Théâtre, tome 2. Edition établie, commentée et précédée d'un Essai par Paul Gorceix, Bruxelles : Édition Complexe, 1999 , p. 46 sq.). Schwester Beatrix wird 1904 von Reinhardt uraufgeführt.

98. Für die Claudel-Aufführung verweist Karl Georg Wendriner auf Botticellis und Ghirlandaios Madonnen sowie, in der Sterbeszene, auf Böcklins Pietà (Breslauer Zeitung v. 7.10.1913, zit. in Landau [Anm. 68], S. 56). Den Tableau-vivant-Charakter der Inszenierung betont neben Wolf (Anm. 84) auch Rudolf Binding, der die «steinerne[n] Bildhaftigkeit » der Gestalten Claudels in der Hellerauer Inszenierung adäquat umgesetzt sieht (Landau (Anm. 68), S. 55). Rilkes Bildvorlagen sind weitgehend unerforscht (Rilke Werke. Kommentierte Ausgabe in vier Bänden, Frankfurt a.M. : Insel, 1996 (künftig zit. als KA mit Bandzahl), hrsg. von Manfred Engel u. a., Band 2, S. 450). 
der Jungfrauengeburt. Violäne wird passiv von der Himmelssphäre affiziert, die sich von oben öffnet. Analog dazu wird ihre « Berufung zum Tode » $(\mathrm{V}, 185)$ am Schluss als Auffahrt in den Himmel vor dem symbolischen Lichtkreuz visualisiert.

Der topischen Raumkonzeption dieser Szenen steht Rilkes mythopoetisches Verfahren diametral gegenüber, das den Bibelmythos durch die freie Kombination verschiedener Text- und Bildvorlagen überschreibt. So gestaltet die Verkündigungsszene des Marien-Lebens einen Raum, in dem sich irdische und himmlische Sphäre in ihrer Sinnlichkeit wechselseitig berühren. Diese Nähe stellt die Mittlerfigur des Engels her, dessen Aufenthalt in menschlichen Regionen «mühsam » ist. Hier ereignet sich keine machtvolle Herabkunft des Göttlichen. Es geht um die Bewältigung von Fremdheit und Distanz, die das Geschehen eines allerersten Liebesakts suggeriert. Erst in dem Moment, in welchem der Blick des Engels mit dem Marias erotisch < zusammenschlägt >, in der Verschmelzung von transzendenter und irdischer Sphäre, entsteht die Präsenz des Heiligen. Die Zeugung beginnt mit dem gemeinsamen Erschrecken. Damit öffnet sich der neue Raum, in dem die musikalische Gottesbotschaft das leibliche Wunder wirkt : «Schaun und Geschautes, Aug und Augenweide/sonst nirgends als an dieser Stelle - : sieh,/ dieses erschreckt. Und sie erschraken beide.// Dann sang der Engel seine Melodie. » ${ }^{99} \mathrm{Im}$ Gegensatz zum jungfräulichen Geschehen zwischen Maria und dem Engel wird die Nähe zur Transzendenz von der sterbenden Maria aktiv herbeigeführt. Das Jenseits kommt ihr dabei so nah, dass es zur begehbaren Exklave ihres Inneren wird. Ein Transit der Seele im Sinne der traditionellen Auffahrt ist daher unnötig :

Sie aber legte sich in ihre Schwäche und zog die Himmel an Jerusalem so nah heran, daß ihre Seele nur, austretend, sich ein wenig strecken mußte : schon hob er sie, der alles von ihr wußte, hinein in ihre göttliche Natur. ${ }^{100}$

Auch dieser Übergang stellt sich als anthropomorpher Beziehungsraum dar. Suggeriert wird die bergende Geste eines göttlichen Vertrauten, die zugleich als Moment innerer Wandlung lesbar ist (" hinein in ihre göttliche Natur»). Maria wird jenseits aller Topik als ebenso übersinnliches wie menschlich-eigenwillig agierendes Wesen präsentiert. Ihre «Lust,/ sich hinzugeben an die innern Zeichen » ${ }^{101}$ liest sich wie die subscriptio für das Vexierspiel von Sinnlichkeit und transzendenter Entgrenzung, welches das Verfahren dieser Gedichte ausmacht. Für

99. KA 2, S. 25 (Mariae Verkündigung).

100. Ibid., S. 33 (Vom Tode Mariae I).

101. Ibid., S. 24 (Die Darstellung Mariae im Tempel). 
Rilke realisiert sich die Erfahrung des Numinosen als Entfaltung der Sinne und nicht, wie bei Claudel, als deren Negierung.

Die Distanz zwischen kontrafaktischer Mythopoesie auf der Deutungsebene des kulturellen Textes bei Rilke und dogmatischer MythenInszenierung auf der Deutungsebene des heiligen Wortes bei Claudel ${ }^{102}$ ist unüberbrückbar. Das Hellerauer Wort- und Lichtdrama produziert einen Rückstoßeffekt : Weil die Rhythmusgruppen von Dalcroze nicht zum Einsatz kommen, erweist sich die Experimentierbühne für Rilke noch einmal als der Ort, an dem jene <Wahrheit〉 der Gebärde vonnöten wäre, die in seiner symbolistischen Poetik und der Rodin-Rezeption eine zentrale Rolle spielt ${ }^{103}$. Seine geteilten Reaktionen auf das Hellerauer Erlebnis lassen sich als Fragmente einer poetologischen Position lesen, die für den Bereich des Dramas zu keiner Affirmation findet. Platzhalter für das fehlende moderne Theatermodell bleiben das ferne Drama der Antike und die Ausdruckskraft der Duse, die für viele Zeitgenossen das Dramatische schlechthin verkörpert. Ihr dichtet Rilke die Rolle seiner weißen Fürstin zu, sie vergleicht er mit Rodins Statuen und träumt von einem " Duse-Theater », in dem ihr existenzielles Pathos seinen Raum fände ${ }^{104}$. Die Leerstelle des Dramatischen entfaltet der Theater-Diskurs in den Aufzeichnungen des Malte Laurids Brigge (1910). Dort stehen Ibsens Dramen für den scheiternden Versuch, in «Dingen » und «Gebärden » sichtbare Äquivalente für die subtilen Gefühlsprozesse des Inneren zu finden, welche die Duse zu verkörpern wei $\beta^{105}$. Auch das Maskenerlebnis im Amphitheater von Orange verweist als literale Vision nur auf das Fehlen der kultischen Gemeinschaft, die einst die dramatische Erneuerung des Mythos ermöglichte und nun vom «Vorwand » der Handlung verdeckt wird ${ }^{106}$. Das Erlebnis einer " antlitzhafte[n] Ordnung » der Schatten in Orange ist durchaus der Wirkungsintention der rhythmischen Räume Appias vergleichbar. Doch bleibt für Rilke < das Antike > selbst dem modernen Bewusstsein nur schattenhaft präsent. Es äußert sich nicht in Festspielen, sondern im Pathos singulärer Gebärden, welche die nicht diskursivierbaren Geheimnisse des Lebens visualisieren ${ }^{107}$.

102. Aleida Assmann : Was sind kulturelle Texte?, in : Literaturkanon-Medienereignis - Kultureller Text. Formen interkultureller Kommunikation und Übersetzung, hrsg. von Andreas Poltermann, Berlin : Schmidt, 1995, S. 232-244. Carl Einstein bezeichnet Claudels Dramen als « Paraphrasen, wenn nicht gar überfüllte Allegorien der Dogmen » : Über Paul Claudel [1916], in : ders. : Werke Band 1 (1907-1918), hrsg. von Hermann Haarmann und Klaus Siebenhaar, Berlin : Fannei \& Walz, 1994, S. 186-194, Zitat S. 193.

103. Angelika Jacobs : Vom Symbolismus zur Stimmung. Zur Poetik des Gefühls beim frühen Rilke, in : Blätter der Rilke-Gesellschaft 25 (2004), S. 99-127; hier S. 112-116. S. $55 \mathrm{f}$.

104. Rilkes Brief an Helene von Nostitz v. 4.11.1913, in : Rilke - von Nostitz (Anm. 50),

105. KA 3, S. 512 (26. Aufzeichnung).

106. Ibid., S. 616f. (64. Aufzeichnung), Zitat S. 616; S. 468 (14. Aufzeichnung).

107. Ibid., S. 617f. (65. Aufzeichnung). 


\title{
Der mittelalterliche Tristan-Stoff in Skandinavien
}

\section{Einführung - Texte in Übersetzung - Bibliographie}

\author{
Hrsg. v. Heiko Uecker
}

2008. Ca. VI, 194 Seiten. Leinen.

$€ 88,-$ [D] / sFr 141,- / *US\$ 130.00

ISBN 978-3-11-020028-7

Im Rahmen seines Kulturprogrammes und der Europäisierung des norwegischen Königshofes ließ König Hákon Hákonarson (geb.1204) kontinentale, insbesondere französische Literatur ins Norwegische übersetzen, darunter die Geschichte von Tristan und Isolde des Robert de Bretagne. Die norwegische Tristram saga ist von zweifacher Bedeutung: Dokument des Kulturimportes vom Kontinent in den Norden und einzige Quelle für die Rekonstruktion von Roberts Werk, das bis auf einige Zeilen verloren ist. Von den lais der Marie de France ist ein Text ebenfalls im 13. Jahrhundert ins Norwegische übersetzt worden. Aus dem 15. Jahrhundert ist eine selbständige isländische Tristrams saga überliefert, die als Reaktion, vielleicht sogar Parodie auf die norwegische Saga verstanden werden muss. Von der Beliebtheit des Stoffes zeugen weiterhin die isländischen, dänischen und färöischen Volksballaden, die ihn in teilweise eigenwilligen Fassungen gestalten. Alle diese Texte werden hier zum größten Teil erstmals in deutscher Übersetzung im Zusammenhang präsentiert.

Preisänderungen vorbehalten. Preise inkl. MwSt. zzgl. Versandkosten.

Die sFr-Preise verstehen sich als unverbindliche Preisempfehlungen. * for orders placed in North America 